\title{
A Pedagogical Model of The Innovative Educational Platform "Youth Academy of Creative Lifetime"
}

\author{
Vitold Albertovich Yasvin, Margarita Nikolaevna Rusetskaya \\ and Mikhail Andreevich Osadchiy
}

\author{
The Pushkin State Russian Language Institute, 6, Akademika Volgina Street, \\ Moscow 117485 Russian Federation.
}

DOI: http://dx.doi.org/10.13005/bbra/1961

(Received: 18 July 2015; accepted: 25 September 2015)

\begin{abstract}
The article presents a pedagogical model of the innovative platform of supplementary education for the senior students of secondary and high school. The mission of the educational platform is to provide a versatile preparation of the members of educational community for the independent and successful realization of their life goals. The synthesis of the competency-based and cultural conformity approaches lies at the heart of the design of educational courses. The content of education includes a number of problem-plagued modules: "Humanistic Philosophy and Worldview", "Personal Development and Lifestyle", "Information and Thinking", "Communication and Interaction", "Project and Organization Management", "Body and Health", "Beauty in Nature and Art", and "Peoples and Countries".During the development of educational courses, the emphasis is made on the formation of the functional literacy (psychological, communicative, political, environmental, consumer, etc.) as the functional basis for the key and special competencies. The educational process consists of six stages: preliminary, primary, individual, group, leadership, and expert (club). The educational process is based on the participation of the education community members in the implementation of the socially significant projects: at first, in the role of performers; then - managers; and at last - experts and consultants. The course content and organization of the educational process provide for the formation and development of the key competencies of a contemporary person: informational-cognitive, civil-social, social-labor, lifestyle, culturalleisure, and personal-organizing.
\end{abstract}

Key words: the designing of the educational system, the content of the youth supplementary education, the competency-based and problem-competency approaches in education, the spheres of the culture of living, the levels of the educational process, the education community.

An essential prerequisite for the successful living of every person within the conditions of the rapidly changing world becomes the strategy of "lifelong learning" (Faure, 1992; Edwards, 1895; Field, \& Leicester, 2000; Shuvalova, 2010; Abramova, 2011; et al.), which is even more topical for those, who are actively seeking to realize

\footnotetext{
* To whom all correspondence should be addressed.
}

their goals and plans. The project of the Youth Academy of Creative Lifetime is aimed at creating an effective system of the educational and developing opportunities for the senior pupils, students, and young professionals.

The modern priorities of the content of education (Karpenko, 1999; Kraevskii, \& Lerner, 2003; Novikov, 2005; Zaikina, 2007; et al.) should provide for as follows: the development of selfdependence and of the ability to self-organization; the ability to assert one's rights, and establishment 
of the high level of legal culture; a willingness to cooperate, and the development of the ability to workmanship; the tolerance for the opinions of others; and the ability to conduct a dialogue, to seek and find the substantive compromises.

The educational system should provide for the experience in self-dependent activity and personal responsibility, i.e. the core competencies defining the contemporary quality of the education content (Delors, 1996; Khutorskoi, 2003; et al.). The competency-based approach is currently widespread in the global educational practice. The competence approach is widespread today in the global educational practice. Basing on the world experience in the implementation of the competency-based approach in education, the following key competencies can be distinguished:

a) A competency in the sphere of self-organization of a personality, which is the development of the methods of self-cognition, self-awareness, self-development, and self-realization; the effective management of time, space, and activity; as well as the formation of the personal image, etc.

b) A competency in the sphere of self-dependent cognitive activity and self-education, which is the perception of ways to search and analyze information from various sources as the foundation for the constant professional growth and success achievement in the public and personal life.

c) A competency in the sphere of public activity, which is mastering the functions of a citizen, elector, consumer, etc.

d) A competency in the sphere of social-labor activity, which is the assessment of personal professional and career opportunities, analysis of the situation on the labor market, the development of the ethics of labor relations, tolerance, etc.

e) A competency in the everyday sphere, which is the healthy lifestyle, family relationships, home improvement, housekeeping, etc.

f) A competency in the sphere of cultural-leisure activity, which is the selection of ways to use one's free time, to ensure one's spiritual development, etc.

The formed competencies are manifested in various spheres of culture, which cover all the diversity of a human living (Subetto, 1993; Flier, 1995; Zapesotskii, 2002; et al.).

The material culture includes the culture of labor and material production, the culture of everyday life and dwelling, the culture of attitude to one's own body and physical culture, and the culture of safety.

The spiritual culture includes the cognitive and intellectual philosophical culture, the moral culture, the culture of self-cognition and selfdevelopment, the artistic culture, the legal culture, the managerial and pedagogical culture, and the religious culture.

The whole system of culture is permeated with the economical culture, the political culture, the ecological culture, and the aesthetic culture.

The distinguished spheres of the culture of living are included into the content of education as the systemic elements of the content of educational courses.

The choice of the mainstream of the educational courses as well as of the individual modules, sections, and topics within the courses is implemented on a basis of full coverage of the spheres of culture and core competencies, on the one hand, and of coverage of the most important issues that are urgent for the development of members of the Academy community The urgency of the problems is determined by the mission of the Academy, which is the multifaceted preparation of the educational community members for the selfdependent and successful implementation of their life goals.

\section{Methods}

The content of the educational courses is designed on the basis of a problem-competency approach (Iasvin, 2010). The potential of this approach is substantiated by a number of advantages. Firstly, it seamlessly combines the intellectual and skill-based components of education. Secondly, its ideology predetermines the designing of the education content according to the criterion of a specific, clearly visible effectiveness. Thirdly, this approach is characterized by a brightly pronounced integrativity integrating a number of corresponding skills and knowledge from various fields of science, art, philosophy, and social practice that relate to the broadest spheres of human living. Fourthly, this approach provides a high level of motivation of students, since it is closely linked with their practical needs and aspirations in life. Finally, fifthly, this approach involves a predominant use of forms and methods of the educational process, 
which are based on stimulating the activity of the students themselves, the actualization and understanding of their life experience, their extensive cooperation therebetween as well as with the teachers, experts, and social environment.

The structural core of the problemcompetency system of the education content is the totality of key competencies. The pedagogical development of all core competencies to a certain degree is possible within the framework of virtually any structural element of this system. However, the formation of each of the core competencies is primarily associated with certain variants of human living, i.e. with the corresponding spheres of culture.

The personality organizing competency is primarily associated with the formation of such spheres of culture as the self-cognition and selfdevelopment, the time management, the personal style, and the individual safety. The cognitiveinformational competency is connected with the cognitive, intellectual, and philosophical cultures. The civil-social competency is associated with the political, moral, and legal cultures. The social-labor competency is connected with the labor, production, economical, and managerial (pedagogical) cultures. The lifestyle competency is associated with the culture of topos (home, dwelling), the environmental culture, and the culture of attitude to one's own body (organism). Finally, the cultural-leisure competency is connected with the aesthetic, artistic, and physical cultures.

Thus, the level of general culture of a human living is determined by the totality of the mastered competencies, and can serve as an integrative criterion for the quality of education.

\section{A model of the education content}

A psychological analysis allows distinguishing the following structural elements of the culture of a human living (Iasvin, 2000), which substantiate the person's choice of a certain behavioral strategy:

a) An aggregate of assumptions of a person in a given sphere of living.

b) The ideological positions, system of values, subjective attitudes of a person to various objects, subjects, processes, and phenomena relating to a given sphere of living.

c) The individual technologies of activities (skills) mastered by a person and associated with a given sphere of living.
The formation of the certain spheres of the living culture is primarily implemented within the framework of the specific problem-focused educational courses.

The educational course of "Humanistic Philosophy and Worldview" considers within its framework the meanings, values, goals, principles, ideology, and strategy of the Academy community; establishes the view of the world, which corresponds to the ideology of the Academy; discusses the "ideal portrait" of a member of the Academy community, etc.

The educational course of "Personal Development and Lifestyle" involves the study of the problem of self-cognition and self-assessment, the reflexion and self-controlling, the management of personal time, space and activities, the development of the sense of purpose, the formation of personal positive image, the provision of personal safety, etc.

The educational course of "Information and Thinking" involves the study of the psychological process associated with the perception, processing, and transmission of information; mastering of the modern information technologies; the development of the abilities to efficiently search, store, remember, analyze, and use the most diversify information.

The educational course of "Communication and Interaction" is focused on the formation in "students" of a partnership-based position in their interactions, and of the tact and tolerance in communication; mastering the techniques of listening and conflict resolving, the development of the ability to understand other people during the process of interaction, etc.

The educational course of "Project and Organization Management" imminently prepares the "students" for their project activity on the following levels of the educational process. It discusses the issues concerning the social projecting, the technologies of the project implementation, expertise, and efficiency monitoring, as well as the issues of leadership, power, motivation of employees, organizational culture of a team, development of the organizations, etc.

The educational course of "Body and Health" includes the basic information on the anatomy and physiology; the formation of the ideas 
on unity of the physical and spiritual features in a person; the acquaintance with the Eastern and Western systems of the organism strengthening and development; the formation in "students" of the responsible attitude towards their health, focus on a healthy lifestyle, etc.

The educational course of "Beauty in Nature and Art" is focused on the aesthetic and general cultural development of "students". Within the framework of this course, it is supposed to get acquainted with the best samples of the world literature and the arts (in museums, concert halls, and exhibitions), to watch and discuss the masterpieces of the cinematography, as well as to get acquainted with the preserved nature of the Russia's national parks. It studies the laws of the beauty perception, and the history of art. It also establishes a creative workshop, in which the "students" can master various creative techniques of self-expression.

The educational course of "Peoples and Countries" is aimed at the formation in "students" of the perception of themselves as of a "Person of the World", whose self-education and selfrealization environment is the entire planet. This course includes the basics of ethnography, and the political and economic geography of the native and foreign countries. A particular emphasis is placed on the study of the country's regions as well as of the border countries, which are promising for the economic and cultural cooperation.

During the process of developing the programs for every educational course, the emphasis is placed on the development of the corresponding intellectual, social, and subject skills. This provides for the achievement of the functional literacy (linguistic, mathematical, psychological, environmental, consumer, etc.) as the functional basis of the core and special competencies.

\section{The principles of the educational process organization \\ The principle of developmental opportunities}

The Youth Academy of Creative Lifetime

is a complex of diversify developmental opportunities for the members of education community. The Academy is functioning as a resource center that provides the community members with the constant access to the educational opportunities. The developmental opportunities of the Academy include the personal and professional potential of all members of the education community who act in various roles (teachers, managers, consultants, and partners for every student; the educational courses; the group and leadership project activities; the informational and methodological resources (literature, audio-, video-, and other electronic materials), which are collected, developed, and cataloged by the specialists of the Academy; the communication with the community members of the Academy and the guests invited.

The developmental opportunities of the Academy are focused on the personality development of the educational community members (the formation of the clear goal-setting, the development of volitional and moral qualities, communicative skills, etc.), as well as on the development of their competencies and functional literacy in the various spheres of living.

Every member of the community is provided with the "Guide to the Educational Resources of the Academy", which presents and systematizes the whole complex of the developmental opportunities and partners of the Academy.

\section{The principle of authenticity}

The Academy provides every member of the education community with the organization of the educational process coherent with his personal life manifestations corresponding to the individual characteristics.

The authenticity (Maslow, 1968; Frankl, 1990; Lobok, 1997; Fromm, 2004; et al.) of the educational process (its content, forms and methods) generates a possibility of functioning in the most favorable rhythm and ensures individual content of education, and such volume and pace of its perception, which are the best to match the individuality and state of a student.

The provision of authenticity is the creation for every one of a natural living environment free from formalism, overorganization, and other detailed characteristics (unfortunately all too familiar by the traditional educational systems).

\section{The principle of free activity}

A community member of the Academy, possessing an extensive access to the developmental resources, decides independently, 
which of them and in which volume he needs to prepare his social project and to implement it in practice.

The experts can argumentatively recommend a community member that he should pass certain educational courses or educational programs due to his personal goals or personality features. However, the decision in any case still remains with the community member himself.

This means in particular that a community member can both complete a full course of training at all levels of the educational process and use only some of the proposed training courses and consulting and diagnostic procedures. A student can also study only the individual topics, trainings, seminars, etc. within the framework of the courses proposed, or he can completely refuse from them immediately starting the implementation of his leadership project.

\section{The principle of expert admittance}

A member of the educational community, who in his own discretion misses the educational courses or the whole educational levels, can be admitted to an appropriate level only after receiving the permission from the community members of the higher corporative ranks.

In order to participate in a group project, it is required to receive permission from the "leader" who manages this project. In order to begin one's own leadership project using the resources of the Academy, it is required to defend the idea of the project according to the corresponding procedure and to receive a positive opinion of the expert commission.

\section{The principle of voluntary partnership}

Every member of the educational community can form groups or join them in order to implement his personal goals only on the basis of the mutual agreements, common interests, and mutual complementation by various resources, etc. No one can be included into the group without the consent of all its members or into the other forms of the involuntary associations of the community members. In particular, no one can be included into the team implementing a group project without the consent of its manager and every member of this team. At the same time, the tolerance and the ability to cooperate with many different people are one of the most important qualities of the community members of the Academy. Accordingly, the community members tend to show loyalty to each other and provide mutual support.

\section{A model of the educational process A preliminary level}

Every potential member of the education community is individually interviewed by the President of the Academy and the experts, who establish a psychological contact, inform on the essence and purpose of the Academy, form a personal impression of the person, and determine the possibilities of the further cooperation with this person. In the event of a positive decision, a number of testing procedures are conducted aimed at diagnosing the peculiarities of the cognitive sphere (thinking, attention, memory, imagination) and of the personal sphere (temperament, character, values, priorities, behavioral strategies, etc.) of a potential member of the education community.

The results of the interview and the psychological diagnosis reveal an individual portfolio, for which an applicant also provides other materials indicating his achievements in various spheres (diplomas, awards, products of artistic activity, etc.). The materials of the portfolio are further analyzed by the experts during the process of monitoring the personality development and consulting.

Based on the results of the interview and the psychological diagnosis, the experts consult an applicant in order to determine the problems and prospects of his self-development, give necessary recommendations, etc.

\section{A primary level}

At the primary level of the educational process, the potential community members of the Academy complete an educational course of "Humanistic Philosophy and Worldview" (40 contact hours). Within the framework of this course, the applicants' view of the world is formed (Petukhov, 1984; Smirnov, 1985; Stetsenko, 1987; et al.). The course is completed with the examination in the form of a "round table", wherein each attendant reads out his philosophical essay on a given topic. The essays are stored in the individual portfolios, and the best of them are published in the anthology of the Academy and posted on the website.

Those attendants, who have successfully completed the educational course of "Humanistic Philosophy and Worldview”, acquire the right to 
consider themselves as the community members of the Academy. They are assigned the first corporate title of a "student". The "students" are enrolled to the individual level of the educational process.

\section{An individual level}

At this level of the educational process, the "students" complete seven educational courses aimed at the formation of all core competencies of a contemporary person, as well as on the development of the functional literacy in all the spheres of the culture of living: "Personal Development and Lifestyle", "Information and Thinking", "Communication and Interaction", "Project and Organization Management”, "Body and Health", "Beauty in Nature and Art", and "Peoples and Countries".

The problematic educational technologies are used as a methodological basis of the organization of an educational process (Dewey, 1899; Lerner, 1969; et al.). The problematic training involves a systematic creation of the problematic situations and the organization of the activities aimed at their resolvement. At the same time, the optimal combination of the self-dependent search activity together with the perception of the "ready" provisions is provided. Therefore, the problematic training ensures the perception of the very way of cognition, i.e. it forms a cognitive competency. Within the framework of the problematic approach, the extensive use is made of the interactive methods, educational games, modelling, programming, computer processing of data, etc. The potential of this method also allows using it for the formation of skills of interaction within a group when solving a common problem; for enhancing the competency in the sphere of preventing and overcoming various conflicts by means of a gaming imitation of the corresponding problematic situations, etc.

Thus, the educational courses are mainly constructed on the basis of the research, seminar, practical, training, gaming, and excursion forms of the educational activity with the minimal use of lectures (up to $15 \%$ of the class time). The meetings are organized with the interesting people, who have realized themselves in the various spheres. All the educational courses are widely using the tasks for independent creative work and group discussion of the results thereof.
The programs of the educational courses are developed on a competitive basis by the involved pedagogues, trainers, and experts. Each course is oriented on 40 contact hours on the basis of 8 contact hours per week during 10 months, which amounts to 320 hours that are divided between 8 courses (including the "Philosophy and Worldview").

The level of the multifaceted individual training is completed with the exams, wherein the "students" should publicly defend their theoretical and practical works on various educational courses, answer the questions, and perform tasks. The creative works are stored in an individual portfolio, and the best thereof are published in the anthology and posted on the website.

The educational systems of the primary and individual levels of the Academy are based on the so-called integrative model (Caluwe, Marx, \& Petry, 1993).

This model is characterized by the broad directionality of the educational process content. In addition to the traditional cognitive content, the education is oriented on the emotional, standard behavioral, social, and expressive (an ability of expressing oneself) development of a personality. The integration of the educational process is strong, wherein the borders between the individual topics, modules, and courses are blurred. In classes, the discussion is often made of the urgent social problems; the individual forms of the organization of an educational activity are developed.

The "students", according to their interests, have a possibility to choose individual educational trajectories, such as a set of educational courses, and the depth of mastering certain modules and topics.

An educational activity is based on allowance for the interests and problems of the "students". The emphasis is placed on their selfrealization, personality growth, and individual responsibility for their own choice. Based on the consultations, the educational courses are amended in accordance with the emerging needs and interests.

The functional of the teachers and experts includes teaching of one or several educational courses or the problem-content modules, the management of the research and creative activity, 
the individual and group work with the "students", as well as their consulting. Thus, every educator equally acts as a subject teacher and a consulting mentor. Such functional requires a high level of social and professional proficiency, the knowledge of the education philosophy and of the educational policy, psychology, and pedagogics. Moreover, the integrative model of the educational system provides freedom for the professional and pedagogical creativity.

The "students", who have successfully completed the individual educational level, are enrolled to the third educational level and assigned a corporate title of a "Master".

\section{A group level}

A group level of the educational process is the participation of the "masters" in the development and implementation of the groupbased socially significant projects.

The technologies of the project- and program-based education are used on this level as the methodological basis for the organization of an educational process.

The project- and program-based approach (Knoll, 1991; Bastian, \& Gudjons, 1993; Guzeev, 1995) is focused on inclusion of the trainees into the existing structures of the social life with their real sociocultural problems, contradictions, and difficulties. The educational process actualizes the types of mental activity associated with the transformation of the reality: designing, planning, programming, forecasting, developing algorithms and scripts, etc.

The designing is carried out within the conditions of small teams with the division of personnel functions. The specialists-consultants, who demonstrate methods for organizing the mental activity and the possibilities of various technological solutions of a given problem, are involved into the working process. A creative environment is generated inside the groups on the basis of the partnership interpersonal relationships.

The practical introduction of the projects (e.g., the environmental or social ones) actualizes the extensive social interactions including those with the governmental institutions. The social activity is formed; the experience of functioning in a civil society is acquired.

The managers of the project groups are represented by the students of the fourth level ("leaders"), who form the project groups from the masters in order to execute their own individual projects. During the first two years of the Academy activity, the project groups are managed by the teachers of educational courses, who suggest their project ideas.

The projects can be focused on supporting and developing various categories and groups of the population, protecting the nature and improving the environment, scientific researches, technical inventions, and technological implementations, political and educational programs, etc. The duration of the projects has no rigid rules of proceedings and depends on the specificity of the project.

The "masters" choose the themes of the projects and the project groups on the basis of the consultations with experts taking into account the individual goals, abilities, and opportunities. The participation in the group projects is a kind of training on probation before the implementation of the personal project on the next educational level. Every “master” participates in several group projects practicing in performance of various roles, functions, and activities.

The experience in group projects ensures the development of the qualities and abilities necessary in future for the implementation of the personal leadership projects: the development and arrangement of a project idea; the choice of partners and their persuasion; the control over the performers; the interaction with the individual personalities, groups, and organizations; the overcoming of the contradictions and disagreements within a team; the preparation and conduction of presentations, etc. During the working process, the participants of the project teams also acquire the experience of critical analysis, reflexion, discussion, public maintenance of one's positions, emotional experience of successes and failures, cooperative and competitive relations, etc. Such a diverse social experience becomes the basis for the formation of core and specific competencies.

The project teams are to prepare the reports on the implemented projects that are published in the anthology and posted on the website. Every team project is to be completed with the presentation, wherein every member of the project group must participate. The presentations 
are of the public nature. They are addressed by the external reviewers with the assessment of the project's success, as well as by the experts with the analysis of the activity of each "master" within the course of the project implementation.

The educational systems of the group and leadership levels are based on the so-called innovative model (Caluwe, Marx, \& Petry, 1993).

The goals and content of education in this model are very similar to the above mentioned integrative model featuring more emphasis on the development of the social activity of the education community members. Such difference is also related to the structural organization of these levels, the units of which are the "modules" - the commands implementing the group projects.

In such model, the experts and teachers fulfil very complicated professional functions, such as the individual and group consulting as well as the expertise of the activity of "masters" and "magisters", and the results thereof on the basis of using the interactive technologies, etc. The qualification of experts and teachers involves the ability of designing and optimally organizing the individual development of the education community members on the basis of the problematic and project technologies, as well as the proficiency in the expressive and socializing activities (acting skills, public speaking, political activity, etc.).

The experts and teachers periodically conduct forums, wherein they summarize and discuss their monitoring of the activity of each "master" and all the project groups. The team of experts and teachers is functioning as an organic unity in the logics of mentoring, is a means for the personality development and socialization of each community member. The experts and teachers are attentive to the circumstances of life and to the state of each "master" and "magister", and of each other. The interactions are aimed at the actualization of their personality growth and social improvement.

The experts and teachers must be unanimous in their views on the essence and goal of education. Such a philosophical unity is achieved during the process of discussions in the “Academ-Club", when the educators, trainers, experts with various points of view (naturally not contradicting with the philosophy of an academic community) produce the common pedagogical strategies. Therefore, inside the pedagogical community of the Academy, a principal agreement is established on the core philosophical and methodological issues.

The project teams possess a high degree of the autonomy. They develop the content of the project activity depending on the specific needs and interests of the members of their own group (the main criterion is the high motivation for selfdevelopment), and also work out their own strategy of the implementation of projects. The functions of the Academy managers are to coordinate the interaction of the project teams and to control the compliance with the community regulations.

A positive opinion of the experts on the activity of a "master" in the group projects means his successful completion of the third level of the educational process, and his enrollment to the fourth level. He is assigned the corporate title of a "Leader".

\section{A leadership level}

The fourth level of the educational process is the development by the "leaders" of the personal projects, and the management of their implementation.

The choice by the "leaders" of the projects is carried out through the consultations with the experts on the basis of individual goals and possibilities.

Before the beginning of the implementation of one's own project, every "leaders" arranges his idea and performs a presentation of the project idea. According to the results of the presentation, the members of the "Academ-Club" vote. A positive result of their voting means the beginning of the leadership project implementation.

In order to implement their own projects, the "leaders" form the groups of 3 to 5 "masters", for whom the participation in a leadership project is the essence of passing a corresponding educational level.

In order to implement their own projects, the "leaders" integrate their personal resources as well as the resources of the Academy community and the resources of the society. The results (products) of the projects in turn become the public domain.

After completing their projects, the "leaders" prepare reports, which are published in 
the anthology and posted on the website. The "leaders" conduct public presentations of the completed projects, which are addresses by the external reviewers with their assessment of the projects success, and also by the experts with the analysis of the "leaders" activities.

A positive opinion of the experts on the activity of a "leader" means his successful completion of the educational process. Hi is assigned the high corporative title of a "Magister". The "magisters" become the members of the "Academ-Club".

\section{The "Academ-Club"}

Alongside with the "magisters", the members of the "Academ-Club" are also the "Watchmen", “Teachers", "Experts”, and "Honored Partners".

A "Watchman" is a highest corporative title within the Academy community. This title is assigned to the members of the "Academ-Club" for their major contribution to the design and development of the Academy ideology; the organization and development of the Academy community; and the material support of the Academy activities.

A "Teacher" is a highest corporative title. It is assigned by the "Watchmen" at the request of the members of the "Academ-Club" to the pedagogues and trainers.

An "Expert" is a highest corporative title. It is assigned by the "Watchmen" at the request of the members of the "Academ-Club" to the specialists and consultants, who ensure the efficient activity of the Academy.

An "Honored Partner" is a highest corporative title. It is assigned by the members of the "Academ-Club" to the private persons being the non-members of the Academy community, and to the organizations for their fruitful cooperation and support of the Academy.

\section{RESULTS}

The pedagogical implementation of the individual educational trajectories of the education community members of the Academy relies on the three substantive components of the educational process, which are the development of the views of the world, the development of the subjective attitudes; and the development of the strategies and individual technologies of the activity associated with various objects and phenomena.

In compliance with these three components of the educational process, we distinguish three groups of methods: the methods for developing views; the methods for developing subjective attitudes; and the methods for developing individual strategies and technologies (Iasvin, 2000).

The designing and pedagogical usage of the methods of each of these groups is regulated by a corresponding methodological principal.

The principal of the mental images development regulates the designing and usage of the methods for developing views. This principle involves the development of the views of the world, which are based both on the scientific information and on the works of art, fiction, various philosophical and religious teachings, etc. The system of the representations of the world is based not only on the experimental activity and its logical perception, but also on the images emerging due to its sensual, emotional and aesthetic mastering.

The methods for developing the system of representations include as follows:

a) The method of labilization (from lat. labilis unstable) is such a purposeful pedagogical impact on the interactions within the personality's view of the world, in the result of which the stability of these connections is broken, and a personality becomes more "sensitive" to the perception of the new information and to the construction on this basis of a new system of interactions within the personality's own view of the world.

b) The method for developing associations (from Lat. associatio - connection) is the development of the mental images through the pedagogical actualization of the associative links between various images within the context of a set problem.

c) The method of the artistic representation of images (from Fr. representation representation) is the development of the mental images during the process of artistic activity.

The principal of the partnership interaction development regulates the designing and usage of the methods for developing the attitudes. This principal involves the pedagogical stimulating of the psychological mechanisms, which allow others to "open" themselves for a personality as the subjects that contribute to the 
formation of the "subject-subjective attitude" in relation to others, which fundamentally changes the attitude to them as well as the nature of the interaction itself.

The methods for developing the system of attitudes include as follows:

a) The method for developing identification (from Lat. identificare - identify) is the pedagogical actualization of positioning oneself into the place of somebody else, of immersing oneself into the life situation of somebody else.

b) The method for developing empathy (from Gr. empatheia - empathy) is the pedagogical actualization of the empathy with the state of another person, of the sympathy with him.

c) The method for developing reflexion (from Lat. reflexio - rearward facing) is the pedagogical actualization of the selfanalysis of one's own behavior in relation to others (of the consciousness).

The principle of the coactivity development (from Lat. coactio - assistance) regulates the designing and usage of the methods for developing the strategies and individual technologies of activities. This principle involves the pedagogical stimulation of the behavioral strategy, which is based on the provision of assistance to others as well as on the mastering of the corresponding subjective and social technologies of such assistance.

The methods for developing the system of strategies and individual technologies include as follows:

a) The method of expectations (from Eng. expectation - expectation) is the pedagogical actualization of the concerned active expectation of an event being planned, of the psychological and technological preparation for this event.

b) The method of the activity ritualization involves pedagogical realization of various traditions and rituals of the activity aimed at assisting and supporting others.

c) The method for developing care involves the pedagogical actualization of the personal activity of the subjects of the educational process aimed at assisting others in difficult situations.

\section{CONCLUSION}

The analysis of trends of the postindustrial society development shows that a sharp necessity for the radical changes in the educational sphere is brewing up in the world. We are talking about the formation of a "global learning society", which is based on the self-education and interactive technologies. The education is considered not simply as a "preparation for life" or mastering of the profession foundations, but also as a true basis of life, which is the continuous process of self-development, self-perfection, exciting and joyful consumption of the intellectual resources provided by the Nature and the Mankind. Such education is based on the freedom of thinking and acting, on the creativity, partnership, and respect for the dignity of each person.

The Youth Academy of the Creative Lifetime is designed exactly in the spirit of a "learning community", and represents a unique educational system aimed at the comprehensive personal development of the young people, who realize themselves in various spheres of the contemporary society. The community members of the Academy learn to dream, design, plan, and transform their life and the surrounding reality striving for the perfection and harmony in all their affairs.

\section{REFERENCES}

1. Abramova, N.V., The Sociological Interpretation of the Concept of "Continuing Professional Education for Adults”. Journal of Sociology and Social Anthropology, 2011; 14(3): 83-103.

2. Guzeev, V.V., Method of Projects as a Special Case of the Integrated Technology of Training. Direktor Shkoly, 1885; 6: 39-47.

3. Zaikina, N.I., Objectives and Content of Modern Education. Pedagogics, 2007; 7.

4. Zapesotskii, A.S., Education: Philosophy, Cultural Studies, and Politics 2002; 456. Moscow: Nauka.

5. Karpenko, M.P., Goals and Objectives of Modern Education. Psychological Science and Education, 1999; 3-4.

6. Lerner, I.Ia., Searching Objectives in Training as a Means of the Creative Abilities Development. Moscow: Nauchnoe Tvorchestvo, 1969.

7. Lobok, A.M., Anthropology of Myth. 
Ekaterinburg, 1997.

8. Novikov, A.M., Methodology of Education 2005; 148. Moscow: Egves.

9. Petukhov, V.V., An Image of the World and the Psychology of Mental Study. The Moscow State University Bulletin, Series 14, Psychology, 1984; 4.

10. Smirnov, S.D., The psychology of Image. The Problem of the Mental Reflection Activity. Moscow, 1985.

11. Stetsenko, A.P., The Concept of an "Image of the World" and Some Problems of the Ontogenesis of Consciousness. The Moscow State University Bulletin, Series 14, Psychology, 1987; 3: 27-33.

12. Subetto, A.I., The Law of Growth of the Ideal Determination in the History and Philosophy of Education. Collection: Education: the Future of Russia and of the Humanity, Saint Petersburg, 1993; 9-13.

13. Kraevskii, V.V., \& Larner, I.Ia., The Theoretical Basis of the General Secondary Education Content 2003; 350. Moscow: Vlados.

14. Flier, A.Ia., Cultural Genesis in the History of Culture. Social Sciences and Modernity, 1995; 3.

15. Frankl, V., A Person in Search of Meaning. Moscow, 1990.

16. Fromm, E., Escape from Freedom. A Person for Himself (Trans. from English). Moscow: OOO “Izdatel'stvo AST", 2004.

17. Khutorskoi, A.V., Core Competencies as a Component of the Personality-Oriented Educational Paradigm. Popular Education, 2003; 2, 58-64.

18. Shuvalova, O.R., International Indicators of the Participation in the Lifelong Learning. Problems of Education, 2010; 2. Moscow: GU-VSchE.

19. Iasvin, V.A., The Educational Environment: from Modeling to Designing 2000; 365. Moscow: Smysl.

20. Iasvin, V.A., A Psychological and Pedagogical Project of the Youth Academy of Creative Lifetime. The Russian State Humanitarian University Bulletin, Series “Psychology”, 2010; 17(61)/10, 162-183. Moscow: RGGU.

21. Bastian, J., \& Gudjons, H., Das Projekt: Projektunterricht. Argumente gegen eine Reduzierung des Projektbegriffs. Pädagogik, Heft 1993; 7-8: 72-73.

22. Caluwe, L. de, Marx, E.C.H., \& Petry, M., School Development: Models and Changes. Leuven, 1993.

23. Delors, JA., Learning: the treasure within. Report to UNESCO of the International Commission on Education for the Twenty-first Century. UNESCO publishing, 1996.

24. Dewey, J., The School and Society. Chicago: University of Chicago Press, 1899.

25. Edwards, R., Behind the Banner. Whither the Learning Society? Adults Learning, 1995; 6(6): 187-189.

26. Knoll, M., Lernen durch praktischen Problemlosen. Die Projektmethode in den U.S.A., 1860-1915. Zeitschrift für internationale Erziehungs-und sozialwissenschaftliche Forschung, 1991; 8: 103-127.

27. Faure, E., Learning to Be: The World Education Today and Tomorrow. Paris: UNESCO, 1992.

28. Field, J., \& Leicester, M. (Eds.)., Lifelong Learning: Education across the Lifespan. London: Routledge, 2000.

29. Maslow, A.H., Toward a Psychology of Being. Litton Education Publishing, 1968. 